\title{
On the Crystallization of Hydroxyapatite under Hydrothermal Conditions: Role of Sebacic Acid as an Additive
}

\author{
Yongjae In, Urasawadee Amornkitbamrung, Min-Ho Hong,* and Hyunjung Shin*
}

Cite This: ACS Omega 2020, 5, 27204-27210

Read Online

ABSTRACT: Hydroxyapatite (HAp) is a major inorganic component in bone minerals and is often used for bone tissue engineering. Herein, we synthesized HAp using sebacic acid as an additive at different $\mathrm{pH}$ values by a hydrothermal method. Sebacic acid, which has two carboxyl group ends of the carbonate chain, binds with $\mathrm{Ca}$ ions during the hydrothermal process to become a crystal nucleation site in (001) and at the same time could act as an inhibitor in a specific direction [i.e., (110)] for the HAp crystal growth. Sebacic acid and the hydroxyl ion $\left(\mathrm{OH}^{-}\right)$are competitively attracted to the

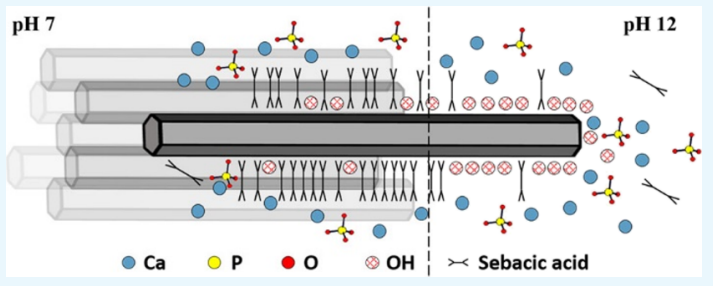
$a(b)$-plane of HAp. Depending on the $\mathrm{pH}$ condition, the crystal growth resulted in different morphologies depending on the ratio of sebacic acid and hydroxide ions. It was confirmed through Fourier-transform infrared spectroscopy and Raman spectroscopy that dicalcium phosphate anhydrous with $\mathrm{HPO}_{4}$ was produced under acidic conditions and HAp was produced under neutral and basic conditions. The plate- and nanorod-HAp crystals' preferential growth along the $c$-axis, which were obtained under neutral and basic conditions, was analyzed by transmission electron microscopy. Growth control in the $c$-axis direction of HAp is necessary for the understanding of crystallization of bone minerals because the mineral inside the collagen fibrils in bone tissue also shows a $c$-axis orientation.

\section{INTRODUCTION}

Hydroxyapatite $\left[\mathrm{Ca}_{10}\left(\mathrm{PO}_{4}\right)_{6}(\mathrm{OH})_{2}, \mathrm{HAp}\right]$ is a naturally occurring mineral. It is also one of the most investigated calcium phosphates (CaPs). Hydroxyapatite is a major inorganic component in hard tissue and can be found in about $60 \%$ of bones, $97 \%$ of tooth enamel, and $70 \%$ of tooth dentin. ${ }^{1,2}$ Bone tissues have a three-dimensional hierarchical structure, especially in the cortical bone section, with a lamella structure with a specific crystallographic orientation., ${ }^{3,4}$ The crystal growth direction of HAp is along with the collagen fibrils that serve as the substrate for bone tissue. The size of the HAp crystal was reported, with the range of $30-50 \mathrm{~nm}$ in length, $15-30 \mathrm{~nm}$ in width, and 2-10 nm in thickness. ${ }^{5,6}$ According to recent research results, the size of the HAp crystal is reported to be $21 \pm 9 \mathrm{~nm}$ in length and $6 \pm 1.5 \mathrm{~nm}$ in width. $^{7}$ Moreover, the $c$-axis of HAp plates were often aligned parallel to the longitudinal direction of collagen fibrils. ${ }^{8}$ Many studies on bone tissue growth and regeneration are ongoing, and from a materials science point of view, the HAp crystal growth process occurs in the body in a specific morphology with micro/nanometer and atomic length scales.

While many different $\mathrm{CaPs}$ are used as inorganic biomaterials, HAp is drawing attention for its excellent biocompatibility, bioactivity, and osteoconductivity. ${ }^{9-11}$ For this reason, the synthesized HAp is usually used as a material for bone tissue engineering. There are many different methods of HAp synthesis, for example, (1) dry methods including solid-state $^{12}$ and mechanochemical methods ${ }^{13}$ and (2) wet methods including sol-gel, ${ }^{14}$ chemical precipitation, ${ }^{15}$ hydrol- ysis, $^{16}$ emulsion, ${ }^{17}$ and hydrothermal ${ }^{18}$ ones. As various synthetic methods of HAp crystals have been developed, the morphology of crystals obtained according to the synthesis method can be adjusted in various ways. Many different synthesis methods result in various morphologies of HAp, for example, sphere, ${ }^{19}$ rod, ${ }^{20}$ and plate-like. ${ }^{21}$ Among them, the hydrothermal process provides the synthesis of specific shaped crystals such as plate and rod shapes at high temperatures and pressures in a controlled manner. ${ }^{22-24}$ In addition, the method enables the synthesis of HAp crystals with high crystallinity and controlled crystal shapes simply by adding additives. As additives, organic compounds are used, for example, ethylenediaminetetraacetic acid $\left(\mathrm{C}_{10} \mathrm{H}_{16} \mathrm{~N}_{2} \mathrm{O}_{8}\right.$, EDTA $)$ which forms chelates with calcium ions. ${ }^{25,26}$ In addition, among the fatty acids having a carboxylic acid group, naturally occurring fatty acids having a dicarboxylic acid group are used as additives. $^{27,28}$ The dicarboxylic acid provides the nucleation site, and the hydrocarbon chain might induce oriented crystal growth of HAp during the hydrothermal process. In addition, organic acids with carboxyl groups are chemisorbed onto the surface of growing crystal grains under hydrothermal

Received: July 9, 2020

Accepted: October 6, 2020

Published: October 16, 2020 

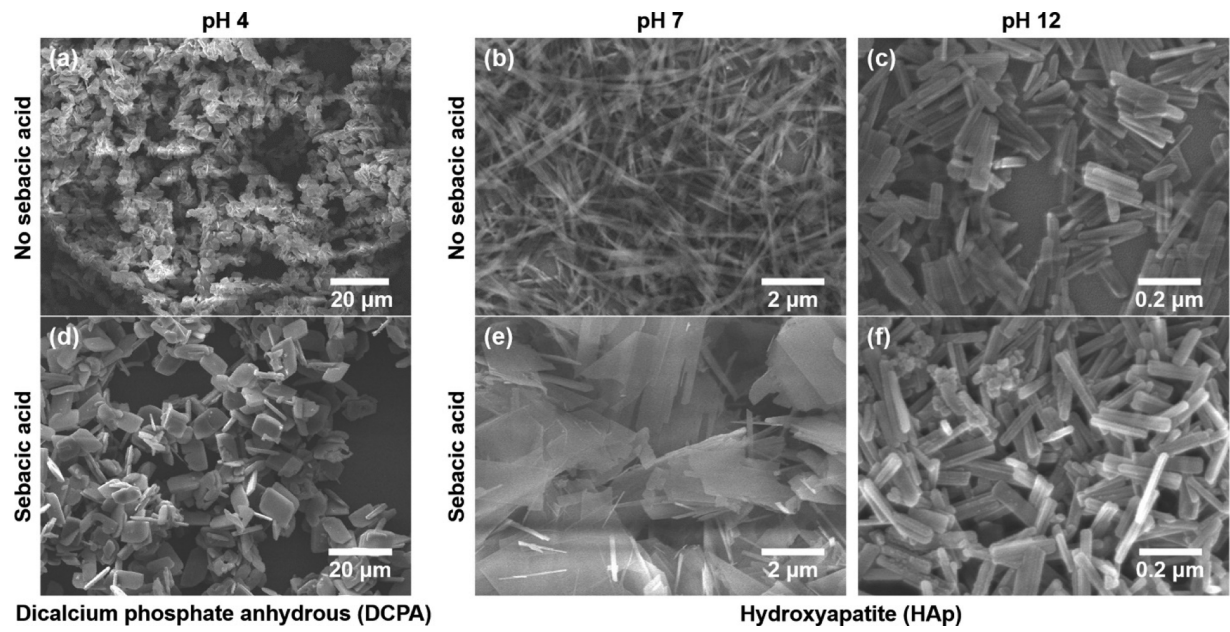

Figure 1. FE-SEM images of DCPA and HAp crystals synthesized at different $\mathrm{pH}$ values, $\mathrm{pH}=4(\mathrm{a}, \mathrm{d}), 7(\mathrm{~b}, \mathrm{e})$, and 12 (c,f) with or without sebacic acid, respectively. The crystal size decreases as the $\mathrm{pH}$ increases. In addition, it can be confirmed that the crystal size is different depending on whether the sebacic acid-structured dicarboxylic acid group is added or not. It is noted that there are different magnifications according to $\mathrm{pH}$ of 4 , 7 , and 12 (see, different scales of 20,2 , and $0.2 \mu \mathrm{m}$, respectively).
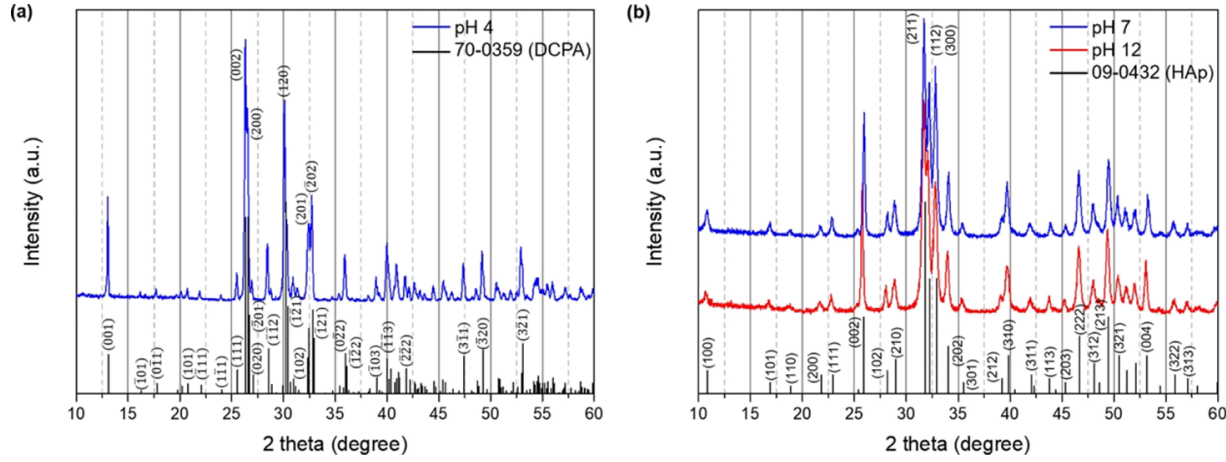

Figure 2. XRD patterns of $\mathrm{CaP}$ crystals synthesized with the additive (sebacic acid) at different $\mathrm{pH}$ values. (a) DCPA synthesized at $\mathrm{pH} 4$ used ICDD 70-0359 as a reference and (b) HAp synthesized at $\mathrm{pH} 7$ and $\mathrm{pH} 12$ using ICDD 09-0432 as a reference. The XRD result of HAp synthesized without the additive at $\mathrm{pH} 7$ is different from the result of HAp synthesized with the additive (Figure S1).

conditions, which help the crystals grow in a specific orientation. These additives can also act as inhibitors of crystal growth for specific orientations in the synthesis of HAp, such as polyaspartic acid or fetuin, present in bone tissue. ${ }^{29,30}$

It has also been reported to affect the final product by various phosphate ions generated depending on the $\mathrm{pH}$ of the solution used for HAp synthesis. The effect of $\mathrm{pH}$ on the crystalline formation of CaPs thus obtained is also related to the properties of the solution containing phosphate ions. ${ }^{19,31,32}$ Triprotic ions in aqueous $\mathrm{H}_{3} \mathrm{PO}_{4}$ are not easy to characterize the concentration differences between $\mathrm{H}_{2} \mathrm{PO}_{4}^{-}, \mathrm{HPO}_{4}{ }^{2-}$, and $\mathrm{PO}_{4}{ }^{3-}$. Many studies have been conducted to synthesize $\mathrm{CaP}$ crystals by adjusting $\mathrm{pH}$ of the solution. ${ }^{33}$ These complexes in equilibrium make their control and prediction difficult in the nucleation and crystal growth process of $\mathrm{CaP}$ crystals. Therefore, in the process of HAp-based bone tissue formation, it can be said that $\mathrm{pH}$ plays a very important role in determining the properties of $\mathrm{CaPs}$.

Based on this, in this study, various forms of HAp were synthesized by adding sebacic acid $\left(\mathrm{C}_{10} \mathrm{H}_{18} \mathrm{O}_{4}\right)$ as an additive in dicarboxylic acid. Sebacic acid with calcium ions has been used as a precursor, and under hydrothermal conditions, they help to grow HAp crystals in the form of plates. In addition, the HAp synthesis was performed through a hydrothermal process of a solution containing phosphate and calcium ions with different $\mathrm{pH}$ values. The $\mathrm{pH}$ affects the chemical composition and crystal growth orientation of the final product. It is confirmed that how the sebacic acid influenced the crystal formation in the crystal growth process by hydrothermal synthesis. In addition, at each $\mathrm{pH}$, by analyzing the results on crystallinity and the chemical composition of the final products, it is possible to see what variables affect the growth of HAp crystals.

\section{RESULTS AND DISCUSSION}

Figure 1 shows scanning emission microscopy (SEM) images of dicalcium phosphate (DCPA, $\mathrm{CaHPO}_{4}$ ) and HAp

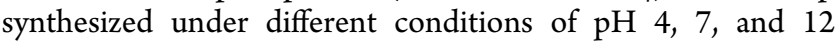
and with/without sebacic acid. It is noted at different magnifications according to $\mathrm{pH} 4,7$, and 12 (see, different scales of 20,2, and $0.2 \mu \mathrm{m}$, respectively.). First of all, regardless of whether or not sebacic acid was added, the crystal size was the largest at $\mathrm{pH} 4$, and it can be seen that as the $\mathrm{pH}$ increases, the crystal size decreases, regardless of the DCPA crystal growth orientation. The synthesized crystals were angled platelike ones, and they have a thickness of about $1 \mu \mathrm{m}$ as shown in Figure 1a,d. Similarly, HAp crystals synthesized at $\mathrm{pH} 7$ are also shown in a plate shape; however, the size is smaller than that of the crystals synthesized at $\mathrm{pH} 4$ (Figure $1 \mathrm{~b}, \mathrm{e}$ ). As shown in Figure 1c,f, SEM images of the HAp crystals 
(a)

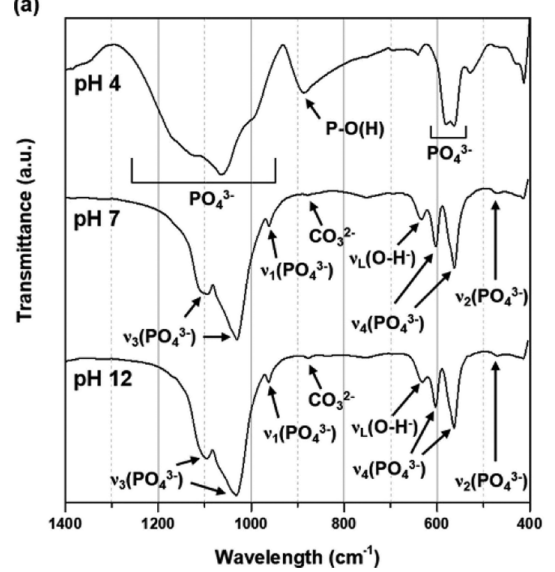

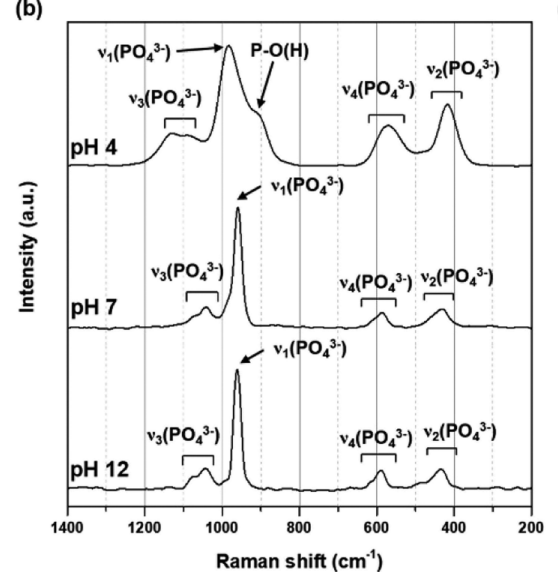

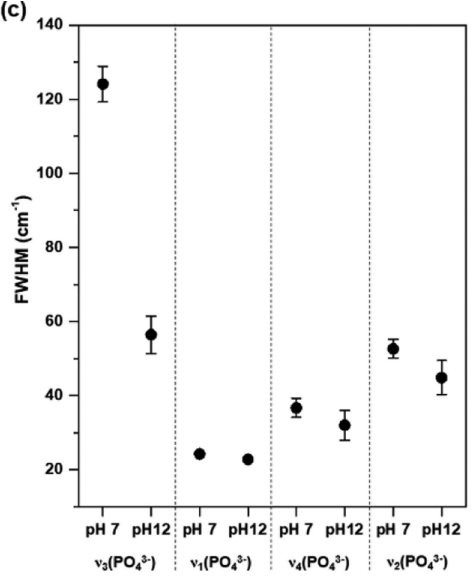

Figure 3. (a) FTIR and (b) Raman spectra for the hydrothermally synthesized $\mathrm{CaP}$ crystals synthesized at $\mathrm{pH} 4,7$, and 12 . $\mathrm{PO}{ }_{4}^{3-}$ peaks are shown in all groups, the difference is that crystals synthesized at $\mathrm{pH} 4$ showing $\mathrm{P}-\mathrm{O}(\mathrm{H})$ stretching and crystals synthesized at $\mathrm{pH} 7$ and $\mathrm{pH} 12$ with $\mathrm{O}-\mathrm{H}$ stretching. (c) Among the Raman spectra results, the fwhm of four representative bands $\left(\mathrm{PO}_{4}{ }^{3-}\right.$ peaks $)$ at $\mathrm{pH} 7$ and 12 . As the pH value increased, the fwhm decreased in all bands.

synthesized at $\mathrm{pH} 12$ show the smallest crystal size with a nanorod shape. Comparing the addition of sebacic acid, the size of $\mathrm{CaP}$ crystals synthesized without the addition of sebacic acid is smaller than that of the crystals synthesized with its addition. It can be inferred from the chemical formation of sebacic acid, which has a chemical structure of dicarboxylic acid $\left(\mathrm{HO}_{2} \mathrm{C}-\mathrm{R}-\mathrm{CO}_{2} \mathrm{H}\right)$ and negatively charged in solution $\left(\mathrm{COO}^{-}\right)$, on a surface that is positively charged by $\mathrm{Ca}^{2+}$ ions in the $\mathrm{CaP}$ crystal, that it can be grown in a long axis. ${ }^{27}$ As the $\mathrm{pH}$ increased, that is, the high concentration of $\mathrm{OH}^{-}$ions influenced the growth of primary unit particles, and under dicarboxylic acid-free conditions, this also seemed to block the chemical binding reactions between $\mathrm{CaP}$ crystal surfaces. ${ }^{34}$

XRD analysis of $\mathrm{CaP}$ crystals hydrothermally synthesized at different $\mathrm{pH}$ values is shown in Figure 2. XRD patterns of hydrothermally synthesized $\mathrm{CaP}$ crystals under $\mathrm{pH} 4$ can be assigned to DCPA $\left(\mathrm{CaHPO}_{4}\right)$, which is in good agreement with ICDD 70-0359 (Figure 2a). The sharp and strong intensity of the XRD peaks indicated a highly crystallized DCPA. According to the XRD result, it was confirmed that the (002) and (200) planes showed a small difference in intensities. This is simply because the synthesized DCPA crystals were oriented with a triclinic crystal system with the $P \overline{1}$ space group. ${ }^{35}$ As shown in the results of the XRD pattern of hydrothermally synthesized $\mathrm{CaP}$ crystals under $\mathrm{pH} 7$ and $\mathrm{pH}$ 12 , all diffraction peaks can be indexed and assigned to a pure HAp using ICDD 09-0432 (Figure 2b). No peaks for any other phases were detected for these samples. The main peaks of HAp can be identified at $2 \theta$ of $31.7^{\circ}, 32.2^{\circ}$, and $32.9^{\circ}$. The $\mathrm{XRD}$ results at $\mathrm{pH} 7$ and $\mathrm{pH} 12$ also show the highest intensity peak of the (211) plane, which corresponds to the peak at $31.7^{\circ}$. The structure of the HAp crystals hydrothermally synthesized at $\mathrm{pH} 7$ and 12 is a hexagonal crystal system with the $\mathrm{PG}_{3} / \mathrm{m}$ space group, which is in good agreement with the reported ones. $^{36}$

FTIR analysis confirmed the functional groups of $\mathrm{CaP}$ crystals hydrothermally synthesized at different $\mathrm{pH}$ values in Figure 3a. Unlike HAp, DCPA has hydrogen phosphate $\left(\mathrm{HPO}_{4}{ }^{2-}\right)$ functional groups, and the difference can be observed in FTIR results. First, as per the results of the hydrothermal synthesis of $\mathrm{CaP}$ crystals at $\mathrm{pH} 7$ and 12 , that is, the group corresponding to HAp, it was confirmed that carbonate ions $\left(\mathrm{CO}_{3}{ }^{2-}\right)$ were substituted. It can be inferred that during the synthesis process, carbonate ions are not present in the reactant, but carbonate-substituted HAp was produced by dissolved $\mathrm{CO}_{2}$ in the ambient. ${ }^{37}$ The region of $1550-1280 \mathrm{~cm}^{-1}$ in wavenumber is represented by the $\nu_{3}$ vibrational mode of carbonate ions. The carbonate ions can be substituted with the sites of hydroxyl $\left(\mathrm{OH}^{-}\right)$and phosphate $\left(\mathrm{PO}_{4}{ }^{3-}\right)$ ions in HAp. In detail, it is known that when the carbonate ions are substituted at the hydroxyl ion position (A type), IR peaks appear at 1544 and $879 \mathrm{~cm}^{-1}$, and IR peaks at 1455 and $1409 \mathrm{~cm}^{-1}$ appear when substituted at the phosphate ion position (B type). ${ }^{37}$ Theoretically, IR spectroscopy identifies four vibration modes for phosphate ions, $\nu_{1}, \nu_{2}, \nu_{3}$, and $\nu_{4}$. As shown in Figure 3a, band peaks at 1091 and 1041 $\mathrm{cm}^{-1}$ in the range of $1190-900 \mathrm{~cm}^{-1}$ are associated with the triply degenerate asymmetric stretching mode $\left(\nu_{3}\right)$, and one at $961 \mathrm{~cm}^{-1}$ was related to the symmetric stretching mode $\left(\nu_{1}\right)$ of $\mathrm{P}-\mathrm{O}$ bonds. The peaks appearing at 601 and $571 \mathrm{~cm}^{-1}$ in the lower range are assigned to the triply degenerate bending $\left(\nu_{4}\right)$ mode of $\mathrm{O}-\mathrm{P}-\mathrm{O}$ bonds. It was observed that the phosphate $\nu_{2}$ band was assigned to a doubly degenerate bending mode of $\mathrm{O}-\mathrm{P}-\mathrm{O}$ bonds at $466 \mathrm{~cm}^{-1} \cdot{ }^{38}$ Furthermore, two unique peaks observed at 3570 and $632 \mathrm{~cm}^{-1}$ were assigned to stretching $\left(\nu_{\mathrm{S}}\right)$ and vibrational $\left(\nu_{\mathrm{L}}\right)$ modes of the structural hydroxyl anion in HAp, respectively (Figure S3). ${ }^{39}$

As a result of Raman spectroscopy of DCPA crystals obtained by hydrothermal synthesis under $\mathrm{pH} \mathrm{4}$, it was confirmed that there was a peak characteristic different from HAp results obtained by synthesis at $\mathrm{pH} 7$ and $\mathrm{pH} 12$. DCPA shows a peak at $891 \mathrm{~cm}^{-1}$, which can be said to be related to the $\mathrm{P}-\mathrm{O}(\mathrm{H})$ stretching mode. ${ }^{40}$ As a result of the Raman spectrum of HAp obtained at $\mathrm{pH} 7$ and $\mathrm{pH}$ 12, the characteristic tetragonal $\mathrm{PO}_{4}{ }^{3-}\left(\nu_{1}\right)$ group peak is observed at $961 \mathrm{~cm}^{-1}$, and the $\mathrm{PO}_{4}{ }^{3-}\left(\nu_{2}\right)$ vibrational mode at $430 \mathrm{~cm}^{-1}$ indicates the $\mathrm{O}-\mathrm{P}-\mathrm{O}$ bending modes. Moreover, the band appearing at $1041 \mathrm{~cm}^{-1}$ is because of the asymmetric stretching of $\mathrm{P}-\mathrm{O}\left(\nu_{3}\right)$, and the peak at $587 \mathrm{~cm}^{-1}$ can be applied as $\mathrm{PO}_{4}{ }^{3-}\left(\nu_{4}\right)$. The Raman spectrum of DCPA showed slightly different results from HAp. We can see that the spectrum assigned to DCPA and HAp phases are visibly distinguishable. The spectrum collected for DCPA particles can be assigned to the DCPA phase according to the available literature data. ${ }^{41}$ 


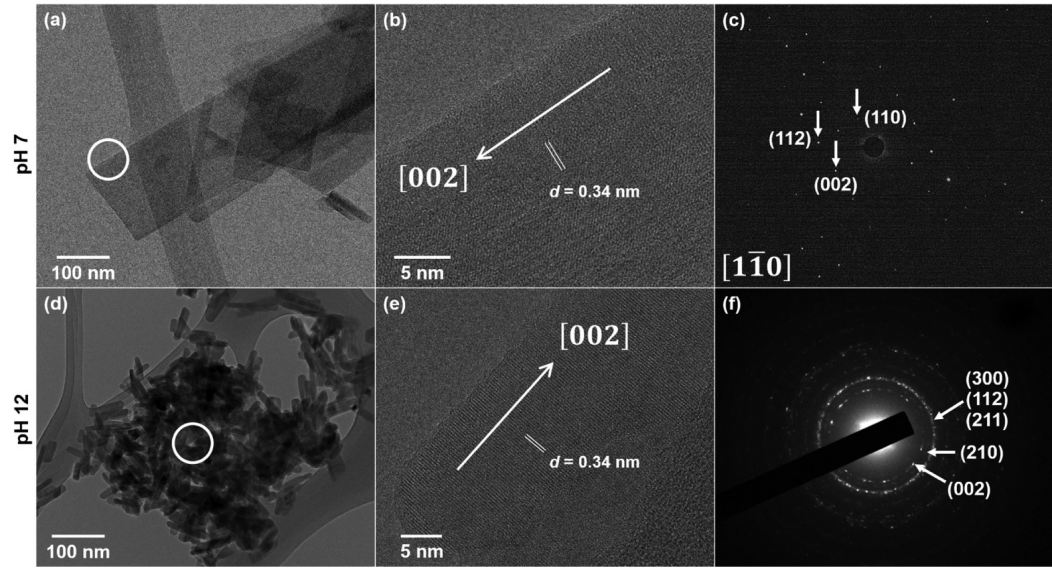

Figure 4. (a,d) TEM images of HAp plates synthesized at pH 7 and 12 and (b,e) HRTEM images of the highlighted area of the TEM images. As shown in the HRTEM image of $\mathrm{pH} 7(\mathrm{~b})$, the $d$-spacing is $0.34 \mathrm{~nm}$, which is in agreement with the results in the [002] direction $(d=0.34 \mathrm{~nm})$. (c) SAED patterns taken normal to the [1 $1 \overline{1} 0$ ] zone axis of the $\mathrm{pH} 7$-synthesized crystals. (f) SAED patterns of the crystal synthesized at $\mathrm{pH} 12$, which is of the highlighted area of the TEM image. The brightest ring patterns correspond to the (300), (112), and (211) planes.
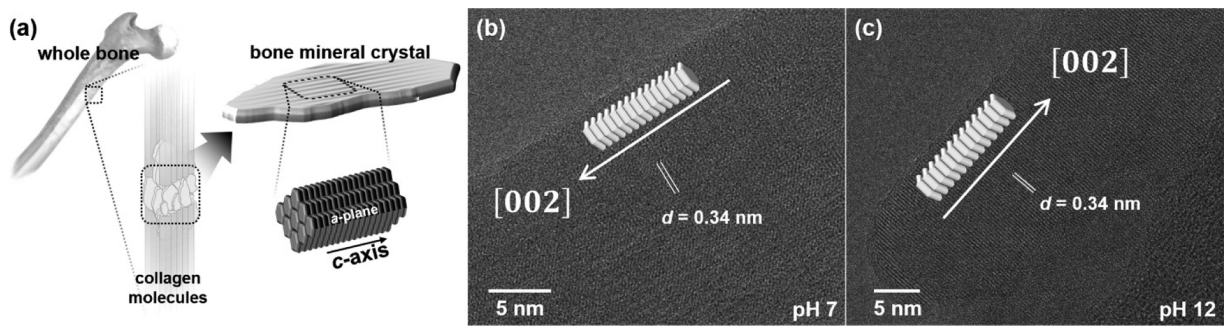

Figure 5. Schematics of HAp with the $c$-axis-orientated crystals in real bone and HRTEM lattice images of the synthesized crystals at pH 7 and 12 . The schematics of HAp formed in the collagen matrix of the cortical bone growth in the $c$-axis direction (a). Plate- and rod-shaped crystals synthesized at $\mathrm{pH} 7$ and 12 were grown in the $c$-axis direction $(\mathrm{b}, \mathrm{c})$. (The $d$-spacing of the (001) plane of HAp is $0.34 \mathrm{~nm} .{ }^{43}$ )

From the DCPA spectrum, we observed the distinct shifts and splitting of the $\mathrm{PO}_{4}{ }^{3-}$ vibrational frequencies. Raman spectrum results of HAp and DCPA are blue-shifted or split compared to the internal modes of the free $\mathrm{PO}_{4}{ }^{3-}$ group. ${ }^{22}$ It is indicated that the strong crystal field in the structure leads to distortion of the spectral lines. When suggested through more complex DCPA spectrum results, there are additional effects on the vibrational characteristic of DCPA crystals. In addition, reinterpreting the Raman spectra results of HAp crystals synthesized at $\mathrm{pH} 7$ and 12 with the fwhm shows that the higher the $\mathrm{pH}$ value in the four representative bands, the lower the fwhm. Research by Londoño-Restrepo et al. proved that the expansion of the Raman band (phonon) is influenced by factors such as various sizes, orientations, and shapes of nanoparticles. ${ }^{42}$ In this study, the decrease in the fwhm for $\mathrm{PO}_{4}{ }^{3-}$ in the crystals synthesized at $\mathrm{pH} 12$ compared to $\mathrm{pH} 7$ is because of the decrease in crystal size and can be verified as the SEM results in Figure 1.

TEM images were observed by adjusting the beam spot size to reduce the damage caused by the electron beam of the HAp crystal. TEM images of the HAp crystals synthesized at $\mathrm{pH} 7$ and $\mathrm{pH} 12$ are shown in Figure 4. As shown in Figure 4a, the HAp crystals synthesized at $\mathrm{pH} 7$ exhibited a plate-shaped morphology with a few $\mu \mathrm{m}$ in length, and the width is less than about $200 \mathrm{~nm}$. The area of the high-resolution TEM (HRTEM) lattice image is the circle in Figure 4a. An interplanar distance of $0.34 \mathrm{~nm}$ corresponds to a lattice spacing of [002] plane in HAp perpendicular to the $c$-axis. The selected area electron diffraction (SAED) pattern of the crystal synthesized at $\mathrm{pH} 7$ (Figure 4c) was also measured at the same area as a circle in Figure 4a. In the SAED pattern with the $[1 \overline{1} 0]$ zone axis, the growth direction was confirmed as the $c$ axis, which is [002] perpendicular to the (002) plane. The SAED pattern presents the only forbidden spots along the $c$ axis ( $00 l$ spots with odd $l$ ) by the $P 6_{3} / m$ space group. As a result, it was confirmed that the synthesized HAp plates were grown along with the $c$-axis in the longitudinal direction as shown by the arrow in the HRTEM image. The TEM image of HAp nanocrystals synthesized at $\mathrm{pH} 12$ (Figure 4d) shows that the size of the nanocrystals is about 50-200 nm in length, similar to the observation in SEM (Figure 1c). The HRTEM image (Figure 4e) showed an interplanar distance of $0.34 \mathrm{~nm}$ and can be inferred to grow along with the $c$-axis as the plates synthesized at $\mathrm{pH}$ 7. All reflections from the (210), (211), (112), (300), and (002) planes can be identified as crystalline HAp. According to the hexagonal HAp structure, three lattice spacings of (300), (112), and (211) are quite close each other with $d=2.72,2.77$, and $2.81 \AA$, respectively; therefore, they can be observed as almost one ring in the SAED pattern (Figure 4f). The growth orientation of nanocrystals can be seen in the SAED patterns. Real bone minerals have also been reported to grow in the $c$-axis.

In the bone mineralization process, there are two types of mineralization: intra- and extrafibrillar. Intrafibrillar mineralization is the nucleation and growth of HAp between the collagen triple helix. ${ }^{44}$ As shown in Figure 5a, the bone tissue is composed of CaPs, organic molecules, mainly type I collagen, and mineralized collagen containing water. In addition to collagen, calcium-binding proteins such as osteocalcin are 
known to mediate the nucleation and growth of plateletshaped HAp crystals. ${ }^{44}$ The most suitable for monomer molecules bound to the HAp surface is the plane parallel to the $c$-axis. As discussed earlier, the results of TEM and XRD confirmed that the HAp crystal growth is along with the $c$-axis; it can be parallel to the collagen fibrils in real bone tissue, as shown in Figure 5 b,c. ${ }^{45,46}$

The schematic diagrams of the growth mechanism of a HAp crystal with sebacic acid are described in Figure 6. According

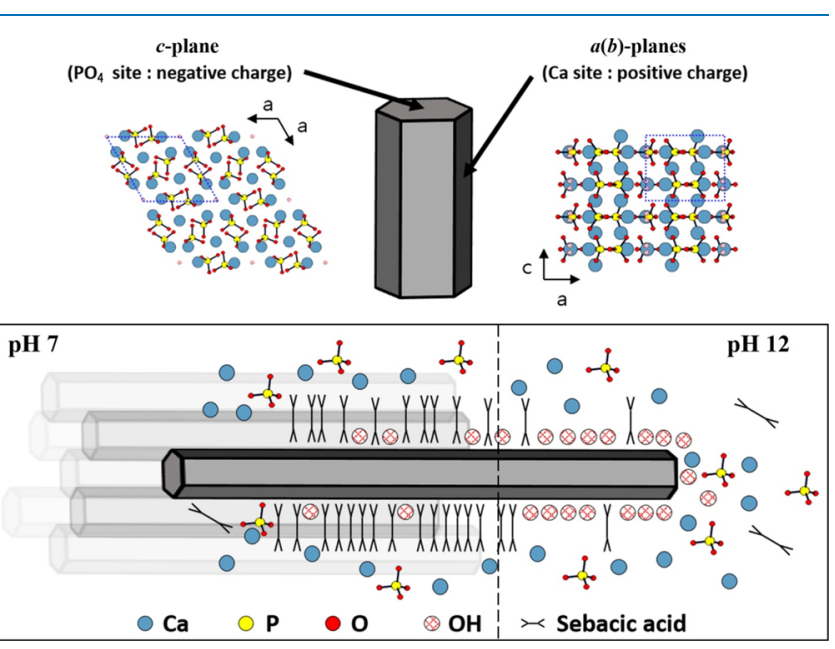

Figure 6. Growth mechanism of a single HAp crystal. In the HAp crystal structure, the $c$-plane is rich in phosphorus ions and the $a(b)$ plane is rich in calcium ions. In the hydrothermal synthesis process, sebacic acid with the carboxyl group $(-\mathrm{COOH})$ and $\mathrm{OH}$ groups is attracted to the $a$-plane and affects nucleation and growth.

to the crystal structure of HAp, which is hexagonal, the hydroxide ions are located in the channel parallel to the $c$-axis. The corresponding $c$ - and $a(b)$-planes differ in composition and atomic arrangement. For example, the $a(b)$-planes are positively charged because it is rich in calcium ions, whereas the $c$-planes are rich in hydroxide ions and are mostly negatively charged. ${ }^{47}$ Therefore, the chemical composition and ions of the solution used in the hydrothermal process shown in this study can be arranged under the influence of the electric charge of each side of the nucleus initially generated. ${ }^{48}$ As shown in Figures 1b,e and 5b, the effect of sebacic acid used as an additive had a great influence on the growth of the hydrothermally synthesized HAp crystals in the plate form under $\mathrm{pH}$ 7. The presence of dicarboxylic acids in solution during the crystal growth of HAp affects the morphology of the resulting crystals $(a(b)$-planes) as well as their growth direction (c-axis). The dicarboxylic acid group in sebacic acid was able to bind to the $a(b)$-planes between crystals, which can be interpreted as inducing crystal growth in a platelet shape. However, as a result of the hydrothermal synthesis of HAp crystals at $\mathrm{pH} 12$ (Figure 5c), it can be determined that the hydroxide ion concentration was affected. In other words, it can be inferred that if the hydroxide ion concentration is high enough, it can also gather on the polar faces such as (002) and inhibit the extension. ${ }^{34}$

\section{CONCLUSIONS}

This study describes the successful use of dicarboxylic acids (i.e., sebacic acid) in the synthesis of HAp through a facile hydrothermal process. It has been confirmed that sebacic acid can accelerate nucleation and act as an inhibitor in the specific direction of $\mathrm{CaP}$ crystal growth. In addition, it has been demonstrated that as the $\mathrm{pH}$ increases during the synthesis process, hydroxide ions decrease in particle size because of the difference in concentration from the dicarboxylic acid provided by sebacic acid. DCPA was synthesized under acidic conditions, and HAp was synthesized under neutral and basic conditions, characterized by XRD, FTIR, and Raman spectroscopy. DCPA and HAp were basically able to be distinguished using the XRD diffraction pattern, and it can be confirmed that they are distinguished by the $\mathrm{P}-\mathrm{O}(\mathrm{H})$ stretching vibration in FTIR and Raman spectroscopy results. In addition, TEM analysis confirmed that the synthetic HAp grows in the same $c$-axis direction as bone minerals. This result suggests that different forms of $\mathrm{CaPs}$ could be synthesized depending on $\mathrm{pH}$, and using an additive is a strategy for controlling the morphologies and orientation of the crystal of HAp.

\section{EXPERIMENTAL SECTION}

Calcium chloride $\left(\mathrm{CaCl}_{2}\right.$, anhydrous powder, $\left.\geq 97 \%\right)$, sodium dihydrogen phosphate dihydrate $\left(\mathrm{NaH}_{2} \mathrm{PO}_{4} \cdot 2 \mathrm{H}_{2} \mathrm{O}, 99 \%\right)$, and sebacic acid (99\%) were purchased from Sigma-Aldrich. Ethanol (99.5\%) and sodium hydroxide $(\mathrm{NaOH}, 97 \%)$ were purchased from Samchun Chemical.

A typical synthetic procedure is described as follows. First, sebacic acid solution (100 $\mathrm{mM}$ ) was prepared by dissolving sebacic acid powder in ethanol. Aqueous solution of $\mathrm{CaCl}_{2}$ $(200 \mathrm{mM})$ was then added to the prepared sebacic acid solution, followed by the addition of $\mathrm{NaOH}$ solution $(1.2 \mathrm{M})$. After stirring for further $30 \mathrm{~min}$, the aqueous solution of $\mathrm{NaH}_{2} \mathrm{PO}_{4} \cdot 2 \mathrm{H}_{2} \mathrm{O}(400 \mathrm{mM})$ was added dropwise, and then, the $\mathrm{pH}$ was adjusted with prepared $\mathrm{NaOH}$ solution $(\mathrm{pH} 4-12)$. The resulting suspension was then transferred into a polytetrafluoroethylene-lined stainless-steel pressure vessel and heated at $180{ }^{\circ} \mathrm{C}$ for $12 \mathrm{~h}$. After this time, the precipitate was separated from the suspension by centrifugation (3000 $\mathrm{rpm}$ for $5 \mathrm{~min}$ at room temperature), washed two times with ethanol/distilled water, and dried at $60{ }^{\circ} \mathrm{C}$ overnight.

The morphology and size of the obtained crystals, which was coated with Pt sputter, were then observed by field-emission scanning electron microscopy (FE-SEM; JSM-7600F, JEOL) operating at $15 \mathrm{kV}$. The crystalline structure of synthesized CaPs was confirmed by XRD (SmartLab, Rigaku) with $\mathrm{Cu} \mathrm{K} \alpha$ radiation $(\lambda=1.5406 \AA)$, operating at $200 \mathrm{~mA}$ and $45 \mathrm{kV}$. The crystalline phase of the synthesized $\mathrm{CaPs}$ was confirmed by comparison with the data reported in the International Centre for Diffraction Data (ICDD) database. The samples of each group were pelleted with $\mathrm{KBr}$, and the molecular structural properties of the synthesized $\mathrm{CaPs}$ were analyzed using an FTIR (Bruker, IFS-66) spectrometer. The Raman spectrum of $\mathrm{CaPs}$ functional groups was taken at room temperature using a confocal Raman microscope (inVia, Renishaw) with linear polarized laser light $(\lambda=532 \mathrm{~nm})$ as the excitation source and a $100 \times$ objective. In order to observe the micrograph acquisition of HAp obtained under the conditions of $\mathrm{pH} 7$ and $\mathrm{pH} 12$ in the synthesized CaPs more precisely, the analysis was performed using transmission electron microscopy (TEM; JEM-2100F/JEM ARM200F, JEOL) operating at an acceleration voltage of $200 \mathrm{kV}$ equipped with a CCD camera. The SAED mode was also conducted to analyze the crystallinity of $\mathrm{CaPs}$ synthesized under different $\mathrm{pH}$ levels. The dried $\mathrm{CaPs}$ 
were dispersed in ethanol and deposited on a lacey carbonfilmed copper-mesh grid and dried at room temperature.

\section{ASSOCIATED CONTENT}

\section{SI Supporting Information}

The Supporting Information is available free of charge at https://pubs.acs.org/doi/10.1021/acsomega.0c03297.

XRD results of synthesized HAp without sebacic acid; $\mathrm{XRD}$ results of synthesized $\mathrm{CaP}$ with sebacic acid at various $\mathrm{pH}$ various; FTIR results based on a wide range of $x$-axis (wavelength; 4000-400 $\mathrm{cm}^{-1}$ ); TGA results (temperature; $50-1300{ }^{\circ} \mathrm{C}$ ); and zeta potential of $\mathrm{CaP}$ crystals synthesized at different $\mathrm{pH}$ values (PDF)

\section{AUTHOR INFORMATION}

\section{Corresponding Authors}

Min-Ho Hong - Nature Inspired Materials Processing Research Center, Department of Energy Science, Sungkyunkwan University, Suwon 16419, Republic of Korea; (1) orcid.org/ 0000-0001-9268-9906; Email: mhong@skku.edu

Hyunjung Shin - Nature Inspired Materials Processing Research Center, Department of Energy Science, Sungkyunkwan University, Suwon 16419, Republic of Korea; (1) orcid.org/ 0000-0003-1284-9098; Email: hshin@skku.edu

\section{Authors \\ Yongjae In - Nature Inspired Materials Processing Research Center, Department of Energy Science, Sungkyunkwan University, Suwon 16419, Republic of Korea \\ Urasawadee Amornkitbamrung - Nature Inspired Materials Processing Research Center, Department of Energy Science, Sungkyunkwan University, Suwon 16419, Republic of Korea}

Complete contact information is available at:

https://pubs.acs.org/10.1021/acsomega.0c03297

\section{Notes}

The authors declare no competing financial interest.

\section{ACKNOWLEDGMENTS}

This research was supported by National Research Foundation of Korea (NRF) grants funded by the Ministry of Science and ICT under contract NRF-2018M3C1B7021994 (Bioinspired Innovation Technology Development Project) and the Ministry of Education contract NRF-2020R1I1A1A01070982 (Basic Science Research Program).

\section{REFERENCES}

(1) Olszta, M. J.; Cheng, X.; Jee, S. S.; Kumar, R.; Kim, Y.-Y.; Kaufman, M. J.; Douglas, E. P.; Gower, L. B. Bone structure and formation: A new perspective. Mater. Sci. Eng., R 2007, 58, 77-116.

(2) Goldberg, M.; Kulkarni, A. B.; Young, M.; Boskey, A. Dentin: structure, composition and mineralization. Front. Biosci., Elite Ed. 2011, E3, 711-735.

(3) Wang, Y.; Azaïs, T.; Robin, M.; Vallée, A.; Catania, C.; Legriel, P.; Pehau-Arnaudet, G.; Babonneau, F.; Giraud-Guille, M.-M.; Nassif, $\mathrm{N}$. The predominant role of collagen in the nucleation, growth, structure and orientation of bone apatite. Nat. Mater. 2012, 11, 724733.

(4) Nair, A. K.; Gautieri, A.; Chang, S. W.; Buehler, M. J. Molecular mechanics of mineralized collagen fibrils in bone. Nat. Commun. 2013, 4, 1724.
(5) Jäger, C.; Welzel, T.; Meyer-Zaika, W.; Epple, M. A solid-state NMR investigation of the structure of nanocrystalline hydroxyapatite. Magn. Reson. Chem. 2006, 44, 573-580.

(6) Weiner, S.; Traub, W.; Wagner, H. D. Lamellar bone: Structurefunction relations. J. Struct. Biol. 1999, 126, 241-255.

(7) Londono-Restrepo, S. M.; Jeronimo-Cruz, R.; Millan-Malo, B. M.; Rivera-Munoz, E. M.; Rodriguez-Garcia, M. E. Effect of the Nano Crystal Size on the X-ray Diffraction Patterns of Biogenic Hydroxyapatite from Human, Bovine, and Porcine Bones. Sci. Rep. 2019, 9, 5915.

(8) Zhai, Y.; Cui, F. Z. Recombinant human-like collagen directed growth of hydroxyapatite nanocrystals. J. Cryst. Growth 2006, 291, 202-206.

(9) Bohner, M. Calcium orthophosphates in medicine: from ceramics to calcium phosphate cements. Injury 2000, 31, D37-D47.

(10) Yoshikawa, H.; Myoui, A. Bone tissue engineering with porous hydroxyapatite ceramics. J. Artif. Organs 2005, 8, 131-136.

(11) Zhou, H.; Lee, J. Nanoscale hydroxyapatite particles for bone tissue engineering. Acta Biomater. 2011, 7, 2769-2781.

(12) Teshima, K.; Lee, S.; Sakurai, M.; Kameno, Y.; Yubuta, K.; Suzuki, T.; Shishido, T.; Endo, M.; Oishi, S. Well-Formed OneDimensional Hydroxyapatite Crystals Grown by an Environmentally Friendly Flux Method. Cryst. Growth Des. 2009, 9, 2937-2940.

(13) Fahami, A.; Ebrahimi-Kahrizsangi, R.; Nasiri-Tabrizi, B. Mechanochemical synthesis of hydroxyapatite/titanium nanocomposite. Solid State Sci. 2011, 13, 135-141.

(14) Kaviyarasu, K.; Mariappan, A.; Neyvasagam, K.; Ayeshamariam, A.; Pandi, P.; Palanichamy, R. R.; Gopinathan, C.; Mola, G. T.; Maaza, M. Photocatalytic performance and antimicrobial activities of HAp-TiO2 nanocomposite thin films by sol-gel method. Surf. Interfaces 2017, 6, 247-255.

(15) Tas, A. C. Synthesis of biomimetic Ca-hydroxyapatite powders at 37 degrees $\mathrm{C}$ in synthetic body fluids. Biomaterials 2000, 21, 14291438.

(16) Almirall, A.; Larrecq, G.; Delgado, J. A.; Martínez, S.; Planell, J. A.; Ginebra, M. P. Fabrication of low temperature macroporous hydroxyapatite scaffolds by foaming and hydrolysis of an alpha-TCP paste. Biomaterials 2004, 25, 3671-3680.

(17) Bose, S.; Saha, S. K. Synthesis and characterization of hydroxyapatite nanopowders by emulsion technique. Chem. Mater. 2003, 15, 4464-4469.

(18) Yan, L.; Li, Y.; Deng, Z.-X.; Zhuang, J.; Sun, X. Surfactantassisted hydrothermal synthesis of hydroxyapatite nanorods. Int. J. Inorg. Mater. 2001, 3, 633-637.

(19) Habraken, W. J. E. M.; Tao, J. H.; Brylka, L. J.; Friedrich, H.; Bertinetti, L.; Schenk, A. S.; Verch, A.; Dmitrovic, V.; Bomans, P. H. H.; Frederik, P. M.; Laven, J.; van der Schoot, P.; Aichmayer, B.; de With, G.; DeYoreo, J. J.; Sommerdijk, N. A. J. M. Ion-association complexes unite classical and non-classical theories for the biomimetic nucleation of calcium phosphate. Nat. Commun. 2013, 4, 1507.

(20) Zhang, X.; Vecchio, K. S. Hydrothermal synthesis of hydroxyapatite rods. J. Cryst. Growth 2007, 308, 133-140.

(21) Neira, I. S.; Kolen'ko, Y. V.; Lebedev, O. I.; Van Tendeloo, G.; Gupta, H. S.; Guitián, F.; Yoshimura, M. An Effective Morphology Control of Hydroxyapatite Crystals via Hydrothermal Synthesis. Cryst. Growth Des. 2009, 9, 466-474.

(22) Suchanek, K.; Bartkowiak, A.; Perzanowski, M.; Marszalek, M. From monetite plate to hydroxyapatite nanofibers by monoethanolamine assisted hydrothermal approach. Sci. Rep. 2018, 8, 15408.

(23) Cao, M.; Wang, Y.; Guo, C.; Qi, Y.; Hu, C. Preparation of ultrahigh-aspect-ratio hydroxyapatite nanofibers in reverse micelles under hydrothermal conditions. Langmuir 2004, 20, 4784-4786.

(24) Liu, J.; Ye, X.; Wang, H.; Zhu, M.; Wang, B.; Yan, H. The influence of $\mathrm{pH}$ and temperature on the morphology of hydroxyapatite synthesized by hydrothermal method. Ceram. Int. 2003, 29, 629-633.

(25) Tomozawa, M.; Hiromoto, S. Microstructure of hydroxyapatiteand octacalcium phosphate-coatings formed on magnesium by a 
hydrothermal treatment at various $\mathrm{pH}$ values. Acta Mater. 2011, 59, $355-363$.

(26) Lak, A.; Mazloumi, M.; Mohajerani, M.; Kajbafvala, A.; Zanganeh, S.; Arami, H.; Sadrnezhaad, S. K. Self-Assembly of Dandelion-Like Hydroxyapatite Nanostructures Via Hydrothermal Method. J. Am. Ceram. Soc. 2008, 91, 3292-3297.

(27) Horiuchi, N.; Shibata, K.; Saito, H.; Iwabuchi, Y.; Wada, N.; Nozaki, K.; Hashimoto, K.; Tanaka, Y.; Nagai, A.; Yamashita, K. Size Control Synthesis of Hydroxyapatite Plates and Their Application in the Preparation of Highly Oriented Films. Cryst. Growth Des. 2018, $18,5038-5044$.

(28) Chen, L. A.; Mccrate, J. M.; Lee, J. C. M.; Li, H. The role of surface charge on the uptake and biocompatibility of hydroxyapatite nanoparticles with osteoblast cells. Nanotechnology 2011, 22, 105708.

(29) Nudelman, F.; Pieterse, K.; George, A.; Bomans, P. H. H.; Friedrich, H.; Brylka, L. J.; Hilbers, P. A. J.; de With, G.; Sommerdijk, N. A. J. M. The role of collagen in bone apatite formation in the presence of hydroxyapatite nucleation inhibitors. Nat. Mater. 2010, 9, 1004-1009.

(30) Kim, D.; Lee, B.; Thomopoulos, S.; Jun, Y.-S. In Situ Evaluation of Calcium Phosphate Nucleation Kinetics and Pathways during Intra- and Extrafibrillar Mineralization of Collagen Matrices. Cryst. Growth Des. 2016, 16, 5359-5366.

(31) Lu, B.-Q.; Garcia, N. A.; Chevrier, D. M.; Zhang, P.; Raiteri, P.; Gale, J. D.; Gebauer, D. Short-Range Structure of Amorphous Calcium Hydrogen Phosphate. Cryst. Growth Des. 2019, 19, 30303038.

(32) Boanini, E.; Gazzano, M.; Bigi, A. Ionic substitutions in calcium phosphates synthesized at low temperature. Acta Biomater. 2010, 6, $1882-1894$.

(33) Lynn, A. K.; Bonfield, W. A novel method for the simultaneous, titrant-free control of $\mathrm{pH}$ and calcium phosphate mass yield. Acc. Chem. Res. 2005, 38, 202-207.

(34) Li, H.; Mei, L.; Liu, H.; Liu, Y.; Liao, L.; Kumar, R. V. Growth Mechanism of Surfactant-Free Size-Controlled Luminescent Hydroxyapatite Nanocrystallites. Cryst. Growth Des. 2017, 17, 2809-2815.

(35) Chen, S.; Krumova, M.; Cölfen, H.; Sturm, E. V. Synthesis of Fiber-like Monetite without Organic Additives and Its Transformation to Hydroxyapatite. Chem. Mater. 2019, 31, 1543-1551.

(36) Feijoo, J.; Fort, R.; Gomez-Villalba, L. S.; Rabanal, M. E.; Ottosen, L. M. Electroprecipitation of Magnesium and Calcium Compounds for Weathering Protection of Ornamental Rocks. Cryst. Growth Des. 2020, 20, 2337-2355.

(37) Kumar, R.; Prakash, K. H.; Cheang, P.; Khor, K. A. Temperature driven morphological changes of chemically precipitated hydroxyapatite nanoparticles. Langmuir 2004, 20, 5196-5200.

(38) Garskaite, E.; Gross, K.-A.; Yang, S.-W.; Yang, T. C.-K.; Yang, J.-C.; Kareiva, A. Effect of processing conditions on the crystallinity and structure of carbonated calcium hydroxyapatite (CHAp). Crystengcomm 2014, 16, 3950-3959.

(39) Slosarczyk, A.; Paszkiewicz, Z.; Paluszkiewicz, C. FTIR and XRD evaluation of carbonated hydroxyapatite powders synthesized by wet methods. J. Mol. Struct. 2005, 744, 657-661.

(40) Tortet, L.; Gavarri, J. R.; Nihoul, G.; Dianoux, A. J. Study of protonic mobility in $\mathrm{CaHPO} 4$ center dot $2 \mathrm{H}(2) \mathrm{O}$ (brushite) and CaHPO4 (monetite) by infrared spectroscopy and neutron scattering. J. Solid State Chem. 1997, 132, 6-16.

(41) Xu, J.; Butler, I. S.; Gilson, D. F. R. FT-Raman and highpressure infrared spectroscopic studies of dicalcium phosphate dihydrate (CaHPO4 center dot $2 \mathrm{H}(2) \mathrm{O})$ and anhydrous dicalcium phosphate (CaHPO4). Spectrochim. Acta, Part A 1999, 55, 28012809.

(42) Londoño-Restrepo, S. M.; Zubieta-Otero, L. F.; Jeronimo-Cruz, R.; Mondragon, M. A.; Rodriguez-Garcia, M. E. Effect of the crystal size on the infrared and Raman spectra of bio hydroxyapatite of human, bovine, and porcine bones. J. Raman Spectrosc. 2019, 50, $1120-1129$.

(43) Ruan, Q.; Liberman, D.; Zhang, Y.; Ren, D.; Zhang, Y.; Nutt, S.; Moradian-Oldak, J. Assembly of Layered Monetite-Chitosan
Nanocomposite and Its Transition to Organized Hydroxyapatite. ACS Biomater. Sci. Eng. 2016, 2, 1049-1058.

(44) Simon, P.; Gruner, D.; Worch, H.; Pompe, W.; Lichte, H.; El Khassawna, T.; Heiss, C.; Wenisch, S.; Kniep, R. First evidence of octacalcium phosphate @ osteocalcin nanocomplex as skeletal bone component directing collagen triple-helix nanofibril mineralization. Sci. Rep. 2018, 8, 13696.

(45) Danilchenko, S.; Kalinkevich, A.; Zhovner, M.; Kuznetsov, V.; Li, H.; Wang, J. Anisotropic aspects of solubility behavior in the demineralization of cortical bone revealed by XRD analysis. J. Biol. Phys. 2019, 45, 77-88.

(46) Murer, F. K.; Sanchez, S.; Alvarez-Murga, M.; Di Michiel, M.; Pfeiffer, F.; Bech, M.; Breiby, D. W. 3D Maps of Mineral Composition and Hydroxyapatite Orientation in Fossil Bone Samples Obtained by X-ray Diffraction Computed Tomography. Sci. Rep. 2018, 8, 10052.

(47) Astala, R.; Stottt, M. J. First-principles study of hydroxyapatite surfaces and water adsorption. Phys. Rev. B: Condens. Matter Mater. Phys. 2008, 78, 075427.

(48) Nagaraj, A.; Munusamy, M. A.; Ahmed, M.; Suresh Kumar, S.; Rajan, M. Hydrothermal synthesis of a mineral-substituted hydroxyapatite nanocomposite material for fluoride removal from drinking water. New J. Chem. 2018, 42, 12711-12721. 